\title{
QUEIJO GORGONZOLA FABRICADO COM LEITE PASTEURIZADO POR EJETOR DE VAPOR E HTST: PARÂMETROS FÍSICO-QUÍMICOS E SENSORIAIS ${ }^{1}$
}

\author{
CRISTIANE GATTINI SBAMPATO², LUIZRONALDO DE ABREU³ e MÚCIO MANSUR FURTADO ${ }^{4}$
}

\begin{abstract}
RESUMO - Este trabalho teve como objetivo avaliar a influência de dois sistemas de pasteurização (High Temperature Short Time - HTST - e ejetor de vapor) nas características físico-químicas e sensoriais do queijo tipo Gorgonzola. As coletas de amostras de queijo e análises foram realizadas aos 5, 25, 45, 65 e 85 dias de maturação. Durante o período de maturação ocorreu aumento gradual de pH, sal/umidade e índice de acidez nos dois tratamentos. Os queijos fabricados com leite pasteurizado pelo sistema HTST obtiveram valores médios de $\mathrm{pH}$ superiores aos dos queijos fabricados com leite pasteurizado pelo sistema ejetor de vapor; os queijos fabricados com leite pasteurizado pelo sistema ejetor de vapor, obtiveram teores de índice de acidez e metilcetonas superiores aos dos queijos fabricados com leite pasteurizado pelo sistema HTST, indicando maior atividade lipolítica nesses queijos. Pela análise sensorial realizada aos 65 dias de maturação, pode se observar que não houve diferença significativa entre os tratamentos em relação à aparência, cor, consistência, textura e sabor. Porém foi observada diferença significativa com relação ao desenvolvimento do mofo e aroma. Os queijos fabricados com leite pasteurizado pelo sistema ejetor de vapor apresentaram maior atividade lipolítica e massa mais macia e fechada.
\end{abstract}

Termos para indexação: pasteurização, lipólise, metilcetonas, maturação de queijos.

\section{GORGONZOLA TYPE CHEESE MANUFACTURED WITH MILK PASTEURIZED BY THE HTST AND STEAM EJECTOR SYSTEMS: PHYSIC-CHEMICAL AND SENSORY PARAMETERS}

\begin{abstract}
The objective of this work was to evaluate the influence of two pasteurization systems (HTST and steam ejector) on the physic-chemical and sensory characteristics of Gorgonzola type cheese. Sampling and analysis were conducted at 5, 25, 45, 65 and 85 days of ripening. Along the maturation period, $\mathrm{pH}$, acidity index, salt/humidity, gradually increased. Cheeses manufactured with milk pasteurized by the HTST system had average values of $\mathrm{pH}$ higher than those manufactured with milk pasteurized by the steam ejector system. Milk pasteurized by the steam ejector system produced cheeses with higher acidity index (lipolysis) and methylketones, which indicate a higher lipolytic activity in these cheeses. The sensory evaluation carried out at 65 days of maturation shows that there was no significant difference between the two treatments, concerning exterior aspects, color, consistence, texture and flavor. However, a significant difference in relation to mold development and aroma was noticed. Cheeses manufactured with milk pasteurized by the steam ejector system, display higher lipolytic activity and mass softer and closer.
\end{abstract}

Index terms: pasteurization, lipolysis, methylketones, cheese ripening.

\footnotetext{
${ }^{1}$ Aceito para publicação em 12 de março de 1999.

${ }^{2}$ Eng. Agrôn., M.Sc., Universidade Federal de Lavras (UFLA), DCA, Caixa Postal 37, CEP 37200-000 Lavras, MG. E-mail: cgattini@ufla.br

${ }^{3}$ Zoot., Ph.D., UFLA/DCA. E-mail: 1rabreu@ufla.br

${ }^{4}$ Bioquímico, Ph.D., Caixa Postal 371, CEP 13276-970 Valinhos, SP.
}

\section{INTRODUÇ̃̃̃O}

O consumo de queijos mofados no Brasil tem, a partir da década de 70 , aumentado significativamente, bem como o interesse por parte das indústrias na elaboração desses produtos. Uma das melhores opções é, sem dúvida, o célebre queijo Gorgonzola, o qual tem sua origem no Vale do Pó, na Itália. Segun- 
do Lourenço Neto (1984) e Furtado \& Lourenço Neto (1994), esse tipo de queijo deve apresentar as seguintes características: ser obtido de leite de vaca, pasteurizado, massa macia, crua, gorda, de cor branca matizada pelo desenvolvimento do mofo e apresentar a seguinte composição físico-química: umidade, $43 \%$ - 45\%; gordura, $28 \%$ - 30\%; proteína, $21 \%$; pH 5,7 - 5,9; teor de sal, 3, $0 \%-3,5 \%$.

O queijo tipo Gorgonzola é maturado por Penicillium roqueforti, que cresce internamente nas olhaduras mecânicas do queijo. Devido à forte ação proteolítica e lipolítica do mofo, o mesmo desenvolve um pronunciado sabor e aroma. Deve ser maturado por 60-120 dias, em câmaras especiais, com 90\% de umidade e temperatura entre $5^{\circ} \mathrm{C}$ e $7^{\circ} \mathrm{C}$, e após 15 a 20 dias de fabricação os queijos são perfurados, para promover penetração de oxigênio no seu interior, o que constitui um dos fatores indispensáveis para o crescimento do Penicillium. Quando cortado, deve apresentar veias azul-esverdeadas bem distribuídas na massa, caracterizadas pelo abundante crescimento do mofo (Furtado, 1987).

Para a obtenção de queijo tipo Gorgonzola com reconhecida qualidade, um fator de grande importância é a qualidade do leite usado em sua fabricação e pasteurização.

No Brasil, as grandes indústrias que fabricam queijos azuis utilizam como processo de pasteurização o sistema High Temperature Short Time (HTST) (sistema de placas), que permite a pasteurização de um grande volume de leite em um espaço de tempo relativamente curto. Já nas pequenas e médias indústrias, o ejetor de vapor é o sistema mais utilizado principalmente na região sul de Minas Gerais (Wolfschoon-Pombo \& Furtado, 1983).

É de conhecimento industrial que os queijos fabricados com leite tratado pelo ejetor de vapor apresentam características sensoriais particulares e diferentes das observadas no queijo elaborado com leite pasteurizado pelo sistema HTST (Ventura et al.,1984), principalmente com referência à cor, textura e retenção de água. O sistema de pasteurização do leite por ejetor de vapor aumenta a retenção de gordura e umidade na massa do queijo; esse aumento pode ser explicado pela homogeneização do leite, causada pela turbulência e alta pressão do vapor na câmara de mistura (Ernstrom, 1980).
Sbampato et al. (1998), avaliando rendimento e retenção de componentes em queijos tipo Gorgonzola fabricados com leite pasteurizado pelos sistemas ejetor de vapor e HTST, concluíram que os melhores rendimentos de fabricação (litro de leite/kg de queijo) foram obtidos com o uso de leite pasteurizado pelo sistema ejetor de vapor. O emprego desse sistema proporcionou melhor aproveitamento de gordura e sólidos totais no queijo, quando comparado com o sistema HTST.

A maturação do queijo é caracterizada por uma série de mudanças físicas, químicas e microbiológicas que afetam os principais componentes do queijo. As mudanças que envolvem lipídeos e proteínas são as mais caraterísticas e significativas (Fernandez-Salgueiro et al.,1988). Durante a maturação dos queijos azuis, o mofo cresce e esporula, intensificam-se os fenômenos de lipólise, oxidação de ácidos graxos e proteólise, e acentua-se o desenvolvimento do flavor. $\mathrm{O} \mathrm{pH}$ do queijo aumenta gradativamente de aproximadamente 4,7 para 6,5 e ocorre metabolização de ácido lático; o queijo desenvolve as manchas azul-esverdeadas que aparecem como veias (Kinsella \& Hwang, 1976).

Entre os componentes do queijo, a gordura exerce um papel preponderante na geração do flavor em queijos, principalmente no tipo Gorgonzola, em que a lipólise fúngica é intensa. Os ácidos graxos de cadeia curta, por serem voláteis, estão entre os mais importantes grupos de compostos contribuintes para o flavor de produtos lácteos, especialmente queijos. Ácidos graxos livres são considerados compostoschaves que contribuem fortemente nas características do flavor de queijos italianos maturados (Ha \& Lindsay, 1993). A natureza dos compostos responsáveis pelo flavor dos queijos azuis e a fisiologia da sua produção pelo $P$. roqueforti são importantes para o entendimento do processo de maturação desses queijos. A hidrólise dos triglicerídeos, com liberação de ácidos graxos, é o resultado de uma ação enzimática, que pode aparecer em todos os produtos lácteos e é denominada lipólise. Sendo a gordura o substrato para variadas reações bioquímicas que levam à formação de aromas e sabor no queijo, grande importância é dada aos agentes responsáveis pela sua hidrólise durante a maturação (Furtado \& Chandan, 1983). Como no sistema ejetor de vapor 
ocorre homogeneização parcial da gordura, favorecendo a atuação das lipases, esse método de pasteurização intensifica as características sensoriais e modifica as propriedades físicas do queijo.

Este trabalho teve como objetivo avaliar a evolução de alguns parâmetros físico-químicos e sensoriais durante a maturação do queijo tipo Gorgonzola fabricado com leite pasteurizado por dois sistemas: HTST e ejetor de vapor.

\section{MATERIAL E MÉTODOS}

Os processos de fabricação dos queijos foram idênticos para cada leite, assim como as quantidades dos constituintes utilizados. A técnica de elaboração foi a descrita por Moraes \& Freitas (1983). As operações de fabricação dos queijos foram efetuadas em tanques de 2.000 litros. O fluxograma de fabricação encontra-se na Fig. 1.

Foram realizadas quatro fabricações em períodos distintos. Para avaliar a evolução dos parâmetros físico-químicos foram coletadas amostras dos queijos durante vários períodos de maturação $(5,25,45,65$ e 85 dias $)$ e análises posteriores foram realizadas.

Após o fim da salga, os queijos foram levados para câmara de maturação, onde permaneceram durante um período de 85 dias. A temperatura da camâra foi mantida a $5^{\circ} \mathrm{C}-7^{\circ} \mathrm{C}$ e umidade a $90 \%$ de acordo com Moraes \& Freitas (1983). Após cinco dias de fabricação, os queijos foram perfurados manualmente, permitindo a introdução de ar no interior do queijo, o que constitui um dos fatores indispensáveis para o desenvolvimento do Penicilium roqueforti.

Nas amostras de queijo foram realizadas as seguintes análises físico-químicas: $\mathrm{pH}$, que foi determinado utilizando-se um potênciometro HANNA (modelo HI 8314), provido de detector de inserção, que foi calibrado previamente. Os teores de extrato seco total (EST) das amostras de queijo foram determinados segundo técnica descrita pela Association of Official Analytical Chemistry (1995). Para determinação de gordura, foi utilizado o método ácido butirométrico Van-Gulik, descrito por Brasil (1981).

Os teores de gordura no extrato seco dos queijos foram determinados pela fórmula:

GES $=(100 \mathrm{x} \% \mathrm{G}) / \% \mathrm{EST}$, onde $\% \mathrm{G}=(\%$ de gordura $)$.

A determinação dos teores de sal foi feita segundo o método descrito por Kosikowski (1977), e os teores de sal na umidade dos queijos foram determinados pela fórmula:

$\% \mathrm{sal} /$ umidade $=$ sal $\times 100 /($ sal + umidade $)$.
O índice de acidez (lipólise) foi determinado por titrimetria, segundo técnicas descritas pela Association of Official Analytical Chemistry (1995). As duas metilcetonas que mais contribuem para o aroma de queijos azuis, 2-heptanona e 2-nonanona foram analisadas pela técnica preconizada por King \& Clegg (1979), com algumas modificações.

Aos 65 dias de maturação, os queijos foram analisados para avaliação dos atributos de aparência, cor, aroma, textura, consistência, desenvolvimento do mofo e sabor, utilizando-se uma escala não estruturada semelhante à utilizada no método de análise Descritivo-Quantitativa. A equipe de provadores foi composta de seis julgadores treinados quanto aos critérios de avaliação. A escala não estruturada é composta de uma linha de $15 \mathrm{~cm}$ de comprimento, contando ainda com pontos-âncora a $1 \mathrm{~cm}$ das extremidades e um ponto-âncora central. Emprega-se uma linha para cada característica de qualidade.

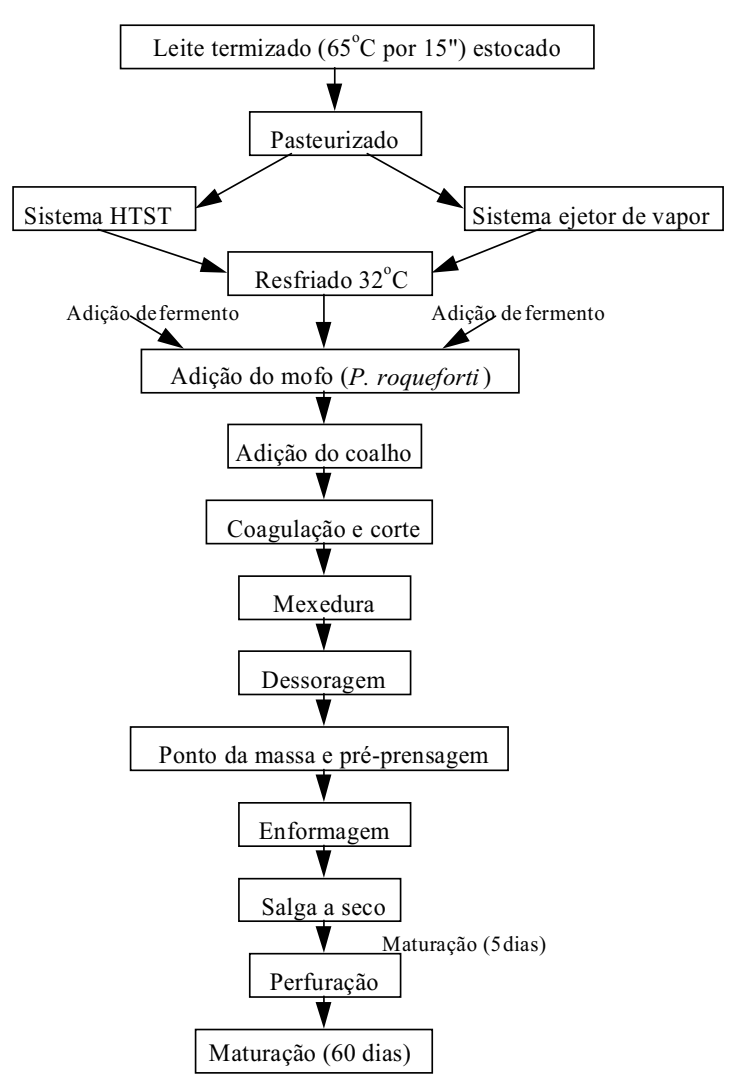

FIG. 1. Fluxograma geral de fabricação do queijo tipo Gorgonzola.

Pesq. agropec. bras., Brasília, v.35, n.1, p.191-200, jan. 2000 
As amostras foram apresentadas à temperatura ambiente e em quantidade suficiente para avaliação sensorial dos queijos. Foram realizadas três repetições para cada tratamento.

Os queijos com 65 dias de maturação foram também submetidos a um teste de aceitação, usando-se para tal uma Escala Hedônica (Jones et al., 1955).

Para realização do teste, utilizaram-se provadores de consumidores potenciais do queijo Gorgonzola. Foram feitas 30 avaliações para cada tratamento.

As folhas de respostas preenchidas pelos provadores foram devidamente organizadas e a classificação dos julgadores foi transformada em valores numéricos para análise estatística dos resultados.

\section{RESULTADOS E DISCUSSÃO}

\section{Composição físico-química do queijo tipo} Gorgonzola após cinco dias de maturação

A composição média de alguns parâmetros físico-químicos do queijo tipo Gorgonzola aos cinco dias de maturação encontra-se na Tabela 1. Os teores médios de umidade, sal, extrato seco total e $\mathrm{pH}$ estão muito próximos dos encontrados por Furtado et al. (1984), e não houve diferença significativa entre os tratamentos.

No início da maturação, é de grande importância considerar o teor de umidade, sal e o $\mathrm{pH}$ do queijo, pois são fatores que influenciam de forma decisiva na maturação. A evolução do $\mathrm{pH}$ é um parâmetro fundamental na fabricação de queijos azuis, pois diminui nas primeiras horas após a fabricação e tende

TABELA 1. Composição média dos queijos tipo Gorgonzola, aos cinco dias de maturação com seus respectivos erros-padrão.

\begin{tabular}{lrr}
\hline Parâmetros & Ejetor de vapor & HTST \\
\hline Umidade (\%) & $47,65 \pm 0,255$ & $45,44 \pm 0,70$ \\
Sal (\%) & $2,13 \pm 0,189$ & $1,83 \pm 0,191$ \\
Sal/umidade (\%) & $4,08 \pm 0,157$ & $3,86 \pm 0,142$ \\
Gordura (\%) & $33,00 \pm 1,179$ & $31,88 \pm 0,471$ \\
Sólidos totais (\%) & $52,35 \pm 0,255$ & $54,56 \pm 0,570$ \\
Gordura no extrato seco (\%) & $63,03 \pm 0,346$ & $58,43 \pm 0,495$ \\
pH & $4,90 \pm 0,011$ & $4,85 \pm 0,007$ \\
\hline
\end{tabular}

Pesq. agropec. bras., Brasília, v.35, n.1, p.191-200, jan. 2000 a aumentar durante a maturação, devido à utilização do ácido lático pelo fungo (Vieira et al.,1982). O comportamento dos teores de ácido lático durante a maturação é essencial para o desenvolvimento do flavor e para a manutenção da qualidade do queijo (Khatoon et al., 1990).

Segundo Moraes \& Freitas (1983), um pH de 5,2 seria normalmente observado 24 horas após a fabricação. Vieira et al. (1982) observaram $\mathrm{pH}$ na faixa de 5,15-5,20 após um dia de fabricação e 4,74-4,85 após sete dias para o queijo azul de Minas. No presente trabalho foram observados valores médios de $\mathrm{pH}$ de 4,90 e 4,85 no quinto dia de maturação, nos queijos tipo Gorgonzola fabricados com leite pasteurizado pelos sistemas ejetor de vapor e HTST respectivamente, sendo, portanto, esses valores, bem próximos dos encontrados por estes autores.

$\mathrm{O}$ teor de umidade do queijo, além de afetar sua consistência, tem grande influência sobre as modificações físico-químicas que ocorrem ao longo da maturação. $\mathrm{O}$ sal dissolvido no meio aquoso, além de modificar o sabor do produto, regula a atividade enzimática e desempenha papel seletivo, evitando o desenvolvimento de microrganismos indesejáveis.

No quinto dia de maturação, os teores médios de sólidos totais encontrados foram de $52,35 \%$ e $54,56 \%$;e os teores de sal foram de $2,13 \%$ e $1,83 \%$ nos queijos fabricados com leite pasteurizado pelos sistemas ejetor de vapor e HTST, respectivamente. Esses resultados se encontram dentro dos padrões estabelecidos para o queijo tipo Gorgonzola (Furtado et al., 1984). Os queijos fabricados com leite pasteurizado pelo sistema ejetor de vapor apresentaram uma coalhada mais mole, em razão do alto teor de umidade e da maior retenção de gordura, que estimulam uma melhor incorporação de sal na massa.

\section{Composição dos queijos durante o período de maturação}

$\mathrm{O} \mathrm{pH}$, durante a maturação, interfere no flavor do queijo, considerando que as lipases e as proteases produzidas pelo Penicillium roqueforti atuam melhor em pH na faixa de 5,5-7,0 (Furtado, 1991). A neutralização gradual da massa tem importância fundamental na maturação do queijo Gorgonzola. Tal fato se deve à dependência do sistema enzimático 
intra e extracelular do mofo às variações do $\mathrm{pH}$ do queijo. Segundo Jolly \& Kosikowiski (1975), no início da maturação há uma destruição metabólica de ácido lático consumido pelo fungo, fazendo elevar lentamente o $\mathrm{pH}$. Ao mesmo tempo, o fungo libera enzimas no meio, e quando o $\mathrm{pH}$ se eleva até uma faixa ideal, as proteases e as lipases atuam mais intensamente. Schlesser et al. (1992) observaram aumento de $\mathrm{pH}$ de 4,4 para 6,4 em queijo Camenbert maturado por 50 dias. Esses mesmos autores relatam que esse aumento pode ser explicado pela assimilação do ácido lático pelo mofo. Portanto, como o mofo neutraliza a acidez do queijo, o $\mathrm{pH}$ aumenta.

Os resultados encontrados (Fig. 2) indicam que houve diferença significativa de $\mathrm{pH}$ entre os tratamentos $(\mathrm{P}<0,05)$. Os queijos fabricados com leite pasteurizado pelo sistema HTST obtiveram valores médios de $\mathrm{pH}$ superiores aos dos queijos fabricados com leite pasteurizado pelo sistema ejetor de vapor. Observa-se que houve aumento gradual do $\mathrm{pH}$ do queijo em conseqüência do processo de metabolização do ácido lático pelo Penicillium roqueforti.

Os resultados encontrados são muito próximos dos verificados por outros autores. Furtado (1978) observou uma evolução do $\mathrm{pH}$ no queijo azul de 4,9-6,0 num período de 30 dias, e Vieira et al. (1982)

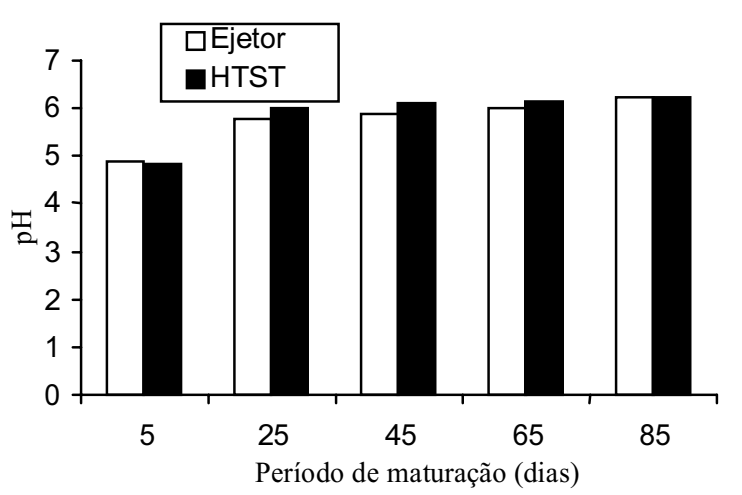

FIG. 2. Valores de pH obtidos durante os diferentes períodos de maturação do queijo tipo Gorgonzola produzido com leite pasteurizado pelos sistemas High Temperature Short Time (HTST) e ejetor de vapor. chegaram a valores na faixa de 4,74-4,85 após sete dias de fabricação e 5,94-6,22 após 60 dias de maturação. Estes mesmos autores relataram que após o $30^{\circ}$ dia, o pH aumenta gradativamente até o final da maturação. Furtado et al. (1984) observaram um pH médio de 5,12 no queijo Gorgonzola com quatro dias de fabricação, e 6,89 após 45 dias de maturação.

Jolly \& Kosikowiski (1975), estudando a maturação do queijo azul mantido a $5^{\circ} \mathrm{C}$ por 75 dias, observaram no final desse período um $\mathrm{pH}$ de 6,1. Wolfschoon-Pombo \& Furtado (1979) relataram aumento do $\mathrm{pH}$ de 5,20 para 6,82 em queijo tipo Chabichou, maturado por 30 dias.

Os resultados médios de $\mathrm{pH}$ um pouco mais baixos observados nos queijos fabricados com leite pasteurizado pelo sistema ejetor de vapor são, provavelmente, em função do maior teor de ácidos graxos livres encontrados nesses queijos, quando comparados aos fabricados com leite pasteurizado pelo sistema HTST.

Os resultados relativos ao aumento progressivo do teor de sal em relação a umidade do queijo, no decorrer da maturação, encontram-se na Fig. 3.

Observa-se que houve um aumento de sal na umidade de 3,86 para $5,59 \%$ e de 4,08 para $5,77 \%$ ao final do período de maturação ( 85 dias), nos queijos fabricados com leite pasteurizado pelos sistemas

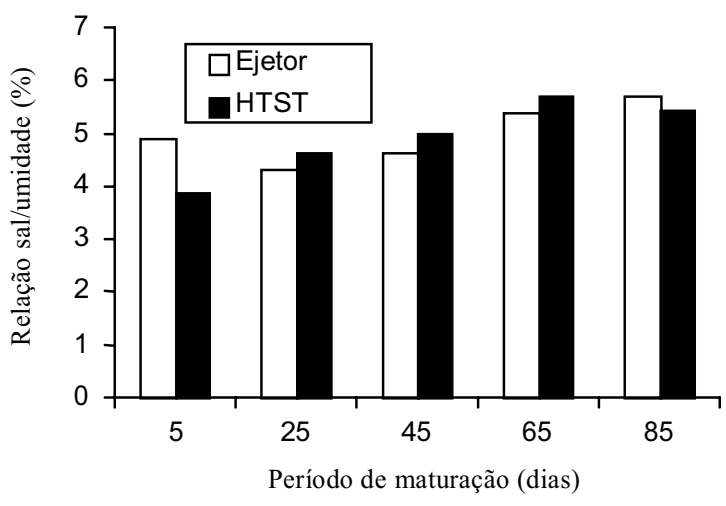

FIG. 3. Valores médios da relação sal/umidade obtidos durante os diferentes períodos de maturação do queijo tipo Gorgonzola produzido com leite pasteurizado pelos sistemas High Temperature Short Time (HTST) e ejetor de vapor. 
HTST e ejetor de vapor respectivamente (Fig. 3). As diferenças entre os tratamentos não foram consideradas estatisticamente diferentes $(\mathrm{P}<0,05)$.

Furtado et al. (1984) observaram aumento no teor de sal na umidade do queijo Gorgonzola de 3 para $5,37 \%$ ao final de 45 dias de maturação.

O aumento do teor de sal durante o período de maturação é devido à perda parcial de umidade que o queijo sofre nesse período, e é variável em função da umidade e do teor inicial de sal no queijo. Os teores de sal devem ser desde o início da maturação compatíveis com as características dos microrganismos responsáveis pela maturação do queijo, pois ao mesmo tempo que o sal atua como agente seletivo, se estiver presente em concentrações muito elevadas pode inibir o crescimento da cultura lática, paralisando a fermentação e comprometendo o desenvolvimento do Penicillium roqueforti no queijo.

$\mathrm{O}$ teor de sal nos queijos afeta os fenômenos físico-químicos e bioquímicos que caracterizam o processo de sua maturação. Os fenômenos de lipólise e proteólise são regulados por enzimas ativadas em teores normais de sal no queijo e inibidas por teores excessivamente elevados. Segundo Furtado (1991), um queijo salgado em excesso possui maturação muito lenta.

Godinho \& Fox (1981) relataram que quando a concentração de sal é mais alta que a adequada, ácidos graxos livres são produzidos mais lentamente, devido ao fato de altas concentrações de sal inibirem a atividade intra e extracelular do Penicillium roqueforti. O teor de umidade do queijo, além de afetar a consistência, tem grande influência sobre as modificações físico-químicas que ocorrem durante a maturação.

Kinsella \& Hwang (1976) e Godinho \& Fox (1981), verificando o efeito do sal sobre o desenvolvimento do Penicillium roqueforti durante a maturação, concluíram que o sal tem forte influência sobre o desenvolvimento do mofo, bem como nos fenômenos de lipólise e proteólise, prevenindo hidrólise excessiva.

Durante o processamento dos queijos, as membranas dos glóbulos de gordura são destruídas, a gordura é atacada pela lipase, e ocorre liberação de ácidos graxos dos triglicerídeos.
O índice de lipólise varia com os diferentes tipos de queijo, dependendo da qualidade do leite e principalmente da tecnologia do processo de fabricação (Caboni et al., 1990).

Os resultados obtidos (Fig. 4) indicam que houve diferença significativa entre os tratamentos $(\mathrm{P}<0,05)$. Os queijos fabricados com leite pasteurizado pelo sistema ejetor de vapor obtiveram índice de acidez (lipólise) superior ao dos queijos fabricados com leite pasteurizado pelo sistema HTST; isso se deve à maior homogeneização do leite durante a pasteurização, que forma glóbulos de gordura menos aglomerados, o que favorece a atuação das lipases. Observa-se, também, um aumento gradual dos índices de acidez, durante o período de maturação, nos dois tratamentos. Gripon (1987) relata que durante o período de maturação ocorre aumento nos níveis de ácidos graxos livres. Macedo et al. (1996), em experimento com queijo Serra, encontraram aumento gradual dos índices de acidez durante o período de maturação.

Caboni et al. (1990) relataram que os níveis de ácidos graxos dos queijos usualmente correspondem aos níveis encontrados no leite usado para sua fabricação. Estes mesmos autores, avaliando lipólise da gordura em 60 amostras de queijo Parmigiano-

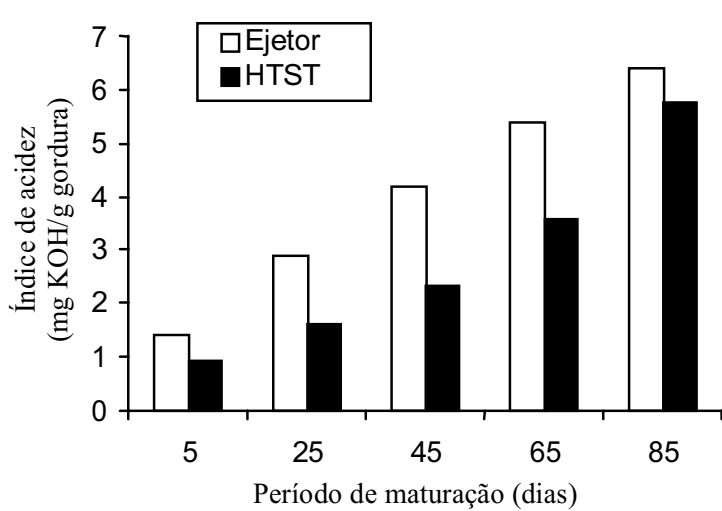

FIG. 4. Valores médios de índice de acidez (lipólise) obtidos durante os diferentes períodos de maturação do queijo tipo Gorgonzola produzido com leite pasteurizado pelos sistemas High Temperature Short Time (HTST) e ejetor de vapor. 
Reggiano, encontraram valores médios de índice de acidez (lipólise) de 6,3 mg de $\mathrm{KOH} / \mathrm{g}$ de gordura.

Godinho \& Fox (1981), estudando lipólise em queijos azuis submetidos a salga seca e em salmoura, observaram níveis de ácidos graxos livres, de, aproximadamente, $1,5 \mathrm{mg}$ de $\mathrm{KOH} / \mathrm{g}$, após uma semana de maturação. Esses mesmos autores observaram aumento significativo do conteúdo de ácidos graxos livres, entre a sétima e a décima semana de maturação.

Os dados referentes às duas metilcetonas mais importantes do queijo tipo Gorgonzola, 2-heptanona e 2-nonanona, aos 25, 45, 65 e 85 dias de maturação encontram-se nas Figs. 5 e 6 . Durante todo esse período de maturação as duas metilcetonas apresentaram, no sistema HTST, teores sempre inferiores ao sistema de ejetor de vapor, sendo que a 2-heptanona apresentou valores sempre maiores que a 2-nonanona.

Como alguns ácidos graxos livres são tóxicos para o $P$. roqueforti, esse mofo promove nesse ácido graxo um ciclo da $\beta$-oxidação, levando à formação de uma metilcetona correspondente com um átomo de carbono a menos, criando com isso um processo de desintoxicação. Comparando esses resultados com índice de acidez (Fig. 4), pode-se observar uma relação direta entre este índice e a concentração de metilcetona nos queijos. Nos queijos elaborados com leite pasteurizado pelo sistema ejetor de vapor, o índice de acidez foi sempre maior que os elaborados com leite pasteurizado pelo sistema HTST, o que correspondeu também a uma maior concentração de metilcetonas no queijo, o que indica que a intensidade de formação desses importantes compostos aromáticos está diretamente relacionada com a presença de ácidos graxos livres no queijo, como relataram Madkor et al. (1987). Segundo Schwartz et al. (1963) e Langlois \& Gallois (1990), o ácido octanóico é um dos mais tóxicos para o P. roqueforti, e assim esse fungo tem a necessidade de metabolizar esse ácido, levando, conseqüentemente, à formação da 2-heptanona, que é um dos compostos mais importantes na composição do aroma de queijos maturados por esse mofo. A porcentagem de heptanona é maior que a de nonanona quando se comparam os dois sistemas de pasteurização, o que indica que o mofo tem, em função da desintoxicação, preferência no metabolismo do ácido octanóico, precursor de 2-heptanona em comparação com o decanóico, precursor de 2-nonanona.

Pela análise sensorial realizada aos 65 dias de maturação pode-se observar que não houve diferença significativa $(\mathrm{P}<0,05)$ entre os tratamentos em relação à aparência, cor, consistência, textura e sabor (Fig. 7). Com relação à coloração, observou-se distribuição homogênea nos dois tratamentos. Os queijos obtidos apresentaram massa macia e quebradiça, indicando que leite pasteurizado pelos sistemas HTST e ejetor de vapor permitem obtenção de

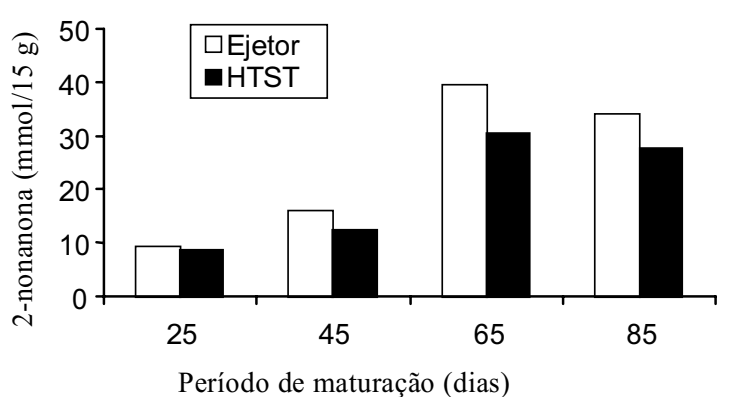

FIG. 5. Valores médios de 2-nonanona obtidos durante os diferentes períodos de maturação do queijo tipo Gorgonzola produzido com leite pasteurizado pelos sistemas High Temperature Short Time (HTST) e ejetor de vapor.

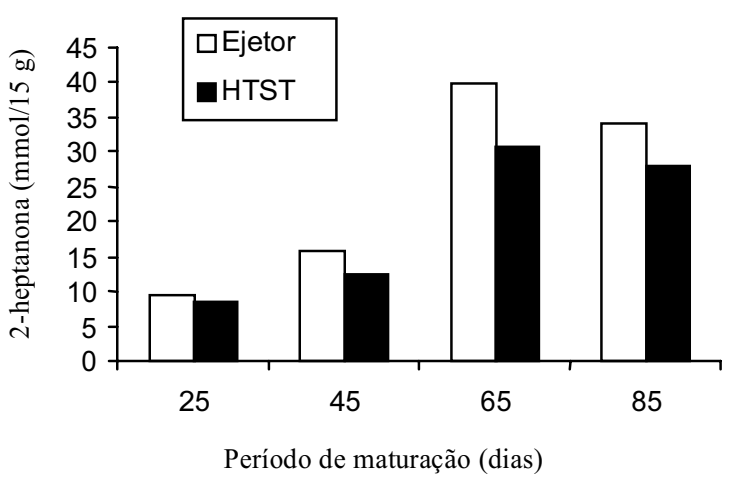

FIG. 6. Valores médios de 2-heptanona obtidos durante os diferentes períodos de maturação do queijo tipo Gorgonzola produzido com leite pasteurizado pelos sistemas High Temperature Short Time (HTST) e ejetor de vapor.

Pesq. agropec. bras., Brasília, v.35, n.1, p.191-200, jan. 2000 
queijo tipo Gorgonzola com características desejáveis de textura e consistência. Esses resultados indicam que os queijos maturaram de maneira adequada. $\mathrm{O}$ desenvolvimento de mofo e aroma dos queijos foram considerados diferentes $(\mathrm{P}<0,05)$, nos tratamentos utilizados (Fig. 7). Os julgadores detectaram desenvolvimento de mofo maior e mais uniforme nos queijos fabricados com leite pasteurizado pelo sistema HTST em relação aos fabricados com leite pasteurizado pelo sistema ejetor de vapor. O menor desenvolvimento de mofo nos queijos fabricados com leite pasteurizado pelo sistema ejetor de vapor pode ser explicado pelos altos teores de ácidos graxos livres encontrados nesses queijos. Kinsella \& Hwang (1976) relataram que altas concentrações de ácidos graxos livres podem ser tóxicas para o mofo.

$\mathrm{O}$ desenvolvimento do mofo tem um efeito acentuado na qualidade do queijo, e esse desenvolvimento deve ser cuidadosamente controlado. No caso de o queijo ter orifícios a mais ou a menos, o desenvolvimento do mofo pode ser excessivo ou escasso, afetando o flavor do produto (Kinsella \& Hwang, 1976). Segundo Gripon (1987), em queijos azuis o desenvolvimento do mofo é fator essencial para o desenvolvimento do aroma, ou seja, se o crescimento do mofo é excessivo ou limitado, o aroma se torna forte ou fraco, respectivamente.

No teste de aceitação, a nota $(7,24)$ do queijo fabricado com leite pasteurizado pelo sistema de ejetor

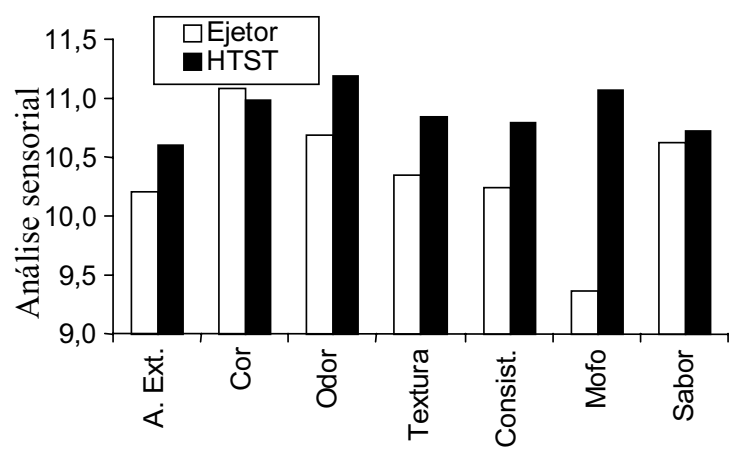

FIG. 7. Valores médios da análise sensorial realizada aos 65 dias de maturação nos queijos tipo Gorgonzola produzidos com leite pasteurizado pelos sistemas High Temperature Short Time (HTST) e ejetor de vapor. de vapor foi semelhante à do queijo fabricado com leite pasteurizado pelo sistema HTST $(7,61)$.

\section{CONCLUSÕES}

1. Os tratamentos utilizados não influem na composição físico-química dos queijos aos cinco dias de maturação, bem como nos teores de sal/umidade.

2. No decorrer da maturação, os queijos fabricados com leite pasteurizado pelo sistema ejetor de vapor apresentam maior índice de acidez, maior concentração de metilcetonas e maior umidade e retenção de gordura, resultando em massa mais macia e fechada.

3. Devido aos altos teores de ácidos graxos livres e massa mais fechada, os queijos fabricados com leite pasteurizado pelo ejetor de vapor possuem menor desenvolvimento de mofo e intensidade de aroma.

4. A análise sensorial não indica diferenças entre os sistemas em relação à aparência, cor, consistência, textura e sabor dos queijos; no teste de aceitação há semelhança dos queijos fabricados com leite pasteurizado, nos dois sistemas.

\section{REFERÊNCIAS}

ASSOCIATION OF OFFICIAL ANALYTICAL CHEMISTRY. Official methods of analysis. 12.ed. Washington, 1995. 1094p.

BRASIL. Secretaria Nacional de Defesa Agropecuária. Laboratório Nacional de Referência Animal. Métodos analíticos oficiais para controle de produtos de origem animal e seus ingredientes. II. Métodos físicos e químicos. Brasília, 1981. Paginação irregular.

CABONI, M.F.; ZANNONI, M.; LERCKER, G. Fat lipolysis in Parmigiano Reggiano Cheese. Scienza e Técnica Lattero-Casearia, Rome, v.41. p.288297, 1990. Supplemento.

ERNSTROM, C.A. Milk-clotting enzymes and their action. In: FUNDAMENTALS of Dairy Chemistry. 2.ed. Westport : AVI, 1980. 360p.

FERNANDES-SALGUEIRO, J.; MARCOS, A.; ALCALA, M.; ESTEBAN, M.A. Proteolysis of cabrales cheese and other European blue cheese 
varieties. Journal of Dairy Research, Cambridge, v.55, n.1 p.141-145, Feb. 1988.

FURTADO, M.M. A arte e a ciência do queijo. 2.ed. São Paulo : Globo, 1991. 297p.

FURTADO, M.M. Defeitos da fabricação de queijos. Juiz de Fora : ILCT, 1987. 392p.

FURTADO, M.M. Roquefort: adaptação da tecnologia para o queijo azul. In: CONGRESSO NACIONAL DE LATICÍNIOS, 1978, Juiz de Fora. Anais. Juiz de Fora : ILCT, 1978. p.51-69.

FURTADO, M.M.; CASAGRANDE, H. de R.; FREITAS, L.C.G. de. Estudo rápido sobre a evolução de alguns parâmetros físico-químicos durante a maturação do queijo tipo Gorgonzola. Revista do Instituto de Laticínios Cândido Tostes, Juiz de Fora, v.39, n.231, p.3-10, jan./fev. 1984

FURTADO, M.M.; CHANDAN, R.C. Efeito do teor de gordura na maturação de um queijo por Penicillium caseicolum. Revista do Instituto de Laticínios Cândido Tostes, Juiz de Fora, v.38, n.225, p.1922, jan./fev. 1983.

FURTADO, M.M.; LOURENÇO NETO, J.P. de M. Tecnologia de queijos: manual técnico para a produção industrial de queijos. São Paulo : Dipemar, 1994. $118 \mathrm{p}$

GODINHO, M.; FOX, P.F. Ripening of blue cheese influence of salting rate on lipolysis and carbonyl formation. Milchwissenschaft, Munich, v.36, n. 8 , p.476-478, 1981.

GRIPON, J.C. Mould-ripened cheeses. In: FOX, P.F. Cheese chemistry, physics and microbiology. London: AVI Publishing, 1987. v.2, Ch.4, p.121149.

HA, J.K.; LINDSAY, R.C. Release of volatile branchedchain and other fatty acids from ruminant milk fats by various lipases. Journal of Dairy Science, Champaign, v.76, n.3, p.677-690, Mar. 1993.

JOLLY, R.C.; KOSIKOWISKI, F.V. Flavor development in pasteurized milk blue cheese by animal and microbial preparations. Journal of Dairy Science, Champaign, v.58, n.6, p.846-852, June 1975.

JONES, L.V.; PERYAM, D.R.; THRUSTONE, L.L. Development of a scale for measuring soldieres food preferences. Food Research, Champaign, v.20, n.5, p.512-520, 1955.
KHATOON, J.A.; HOSSAIN, M.A.; JOSHI, V.K. Biochemical changes during ripening of cheddar cheese made from cow and goat milk. Milchwissenschaft, Cork, v.45, n.7, p.436-439, 1990.

KING, R.D.; CLEGG, G.H. The metabolism of fatty acids, methy ketone and secondary alcohols by $P$. raqueforti in Blue Cheese Slurries. Journal of the Science of Food and Agriculture, Londres, v.30, n.2, p.197-202, Feb. 1979.

KINSELLA, J.E.; HWANG, D.H. Enzymes of Penicillium roqueforti involved in the biosynthesis of cheese flavor. Critical Reviews in Food Science and Nutrition, Cleveland. v.8, n.1, p.191-228, 1976.

KOSIKOWSKI, F. Cheese and fermented milk foods 2.ed. Edwards: Ann. Arbor, 1977. 711p.

LANGLOIS, D.; GALLOIS, A. New results in the volatile odorous compounds of french cheese. Lait, Paris, v.70, p.89-106, 1990.

LOURENÇO NETO, J.P. de M. Tecnologia de fabricação do queijo Gorgonzola no Brasil. Revista do Instituto de Laticínios Cândido Tostes, Juiz de Fora, v.39, n.235, p.43-46, set./out. 1984.

MACEDO, A.C.; COSTA, M.L.; MALCATA, F.X. Assessment of proteolysis and lipolysis in Serra Cheese: effects of axial cheese location, ripening time and lactation season. Lait, Paris, v.76, n.4, p.363370, 1996.

MADKOR, S.; FOX, P.F; SHALABI, S.I.; METWALLI, N.H. Studies on the ripening of Stilton cheese: Lipolysis. Food Chemistry, England, v.25, n.1, p.93$109,1987$.

MORAES, J.M.; FREITAS, L.C.G. Adaptação da tecnologia de fabricação de queijos de origem italiana - queijo Gorgonzola. Revista do Instituto de Laticínios Cândido Tostes, Juiz de Fora, v.38, n.227, p.33-39, maio/jun. 1983.

SBAMPATO, C.G.; ABREU, L.R. de; FURTADO, M.M.; MENDONÇA, A.T. Influência de dois sistemas de pasteurização na composição do leite e do soro do queijo tipo Gorgonzola. Revista do Instituto de Laticínios Cândido Tostes, Juiz de Fora, v.53, n.305, p.15-22, set./dez. 1998.

SCHLESSER, J.E.; SCHMIDT, S.J.; SPECKMAN, R. Characterization of chemical and physical changes in Camembert Cheese during ripening. Journal of

Pesq. agropec. bras., Brasília, v.35, n.1, p.191-200, jan. 2000 
Dairy Science, Champaign, v.75, n.7, p.1753-1760, Jul. 1992.

SCHWARTZ, D.P.; HALLER, M.S.; KEENEY, N. Direct quantitative isolation of monocarbonyl compounds from fats and oils. Analytical Chemistry, Washington, v.35, n.13, p.2191-2194, Dec. 1963.

VENTURA, R.F.; FURTADO, M.M.; WOLFSCHOON, A.F.; LOURENÇO NETO, J.P. de M.; LIMA, A. de. Queijo prato - comparação de fabricação usando leite pasteurizado por sistema de placas e ejetor de vapor. Revista do Instituto de Laticínios Cândido Tostes, Juiz de Fora, v.39, n.235, p.59-70, set./out. 1984
VIEIRA, S.D.A.; LOURENÇO NETO, J.P.M.; NEVES, B.S. Queijo azul de Minas. Informe Agropecuário, Belo Horizonte, v.8, n.88, p.33-36, 1982.

WOLFSCHOON-POMBO, A.F.; FURTADO, M.M. Changes in soluble nitrogen, $\mathrm{pH}$ and lactic acid during ripening of chabichou-type cheese. Journal of Food Protection, Iowa, v.42, n.8, p.666-669, Aug. 1979.

WOLFSCHOON-POMBO, A.F.; FURTADO, M.M. Uma tecnologia a ser preservada: o queijo prato da região sul de Minas Gerais. Revista Brasileira de Tecnologia, São Paulo, v.14, n.5/6, p.50-54, set./dez. 1983. 